\title{
Satisfactory mid-term outcomes of condylar-constrained knee implants in primary total knee arthroplasty: clinical and radiological follow-up
}

Fabio Mancino ${ }^{1,2^{*}}$ (D) Ivan De Martino ${ }^{1}$, Aaron Burrofato ${ }^{3}$, Carmine De leso ${ }^{4}$, Maristella F. Saccomanno ${ }^{1}$, Giulio Maccauro ${ }^{1,2}$ and Vincenzo De Santis ${ }^{5}$

\begin{abstract}
Background: The purpose of this study was to evaluate (1) the reoperation rates and survivorship for septic and aseptic causes, (2) radiographic outcomes, and (3) clinical outcomes of condylar-constrained knee (CCK) implants used in primary total knee arthroplasty (TKA) with severe coronal deformity and/or intraoperative instability.

Materials and methods: A consecutive series of CCK implants in primary TKA was retrospectively evaluated in patients with severe coronal deformities. Forty-nine patients (54 knees) were included with a mean follow-up of 9 years (range 6-12). All patients were treated with a single-design, second-generation CCK implant. The primary diagnosis was osteoarthritis in 36 knees, post-traumatic arthritis in 7 knees, and rheumatoid arthritis in 4 knees. Preoperatively, standing femorotibial alignment was varus in 22 knees and valgus in 20 knees.

Results: At a mean follow-up of 9 years, overall survivorship was 93.6\%. Two knees (4.3\%) required revision for periprosthetic joint infection. One knee (2.1\%) required subsequent arthroscopy due to patellar clunk syndrome. At final follow-up, no evidence of loosening or migration of any implant was reported, and the mean Knee Society knee scores improved from 43 to 86 points $(p<0.001)$. The mean Knee Society function scores improved to 59 points $(p<0.001)$. The average flexion contracture improved from $7^{\circ}$ preoperatively to $2^{\circ}$ postoperatively and the average flexion from $98^{\circ}$ to $110^{\circ}$. No knees reported varus-valgus instability in flexion or extension.

Conclusion: CCK implants in primary TKA with major coronal deformities and/or intraoperative instability provide good midterm survivorship, comparable with less constrained implants. In specific cases, CCK implants can be considered a viable option with good clinical and radiographic outcomes. However, a higher degree of constraint should be used cautiously, leaving the first choice to less constrained implants.
\end{abstract}

Level of evidence Therapeutic study, level IV.

Keywords: Constrained condylar knee, Varus-valgus constraint, Total knee arthroplasty, Primary TKA, Valgus deformity, Coronal deformity, Survivorship, Instability, Joint laxity, CCK

*Correspondence: fabio_mancino@yahoo.com

1 Division of Orthopaedics and Traumatology, Department of Aging, Neurological, Orthopaedic and Head-Neck Studies, Fondazione Policlinico Universitario Agostino Gemelli IRCCS, 00168 Rome, Italy

Full list of author information is available at the end of the article

\section{Introduction}

Total knee arthroplasty (TKA) is one of the most frequent orthopedic surgical procedures, with $>600,000$ surgeries performed every year in the United States and the number is projected to grow by $673 \%$ in 2030 [1]. Despite the excellent reported results, with registries 
reporting survivorship of $>95 \%$ after 10 years [2, 3], aseptic loosening and instability are among the most common failure mechanisms requiring revision TKA [4-6].

In the majority of primary TKAs, a well-balanced and stable knee is achieved through soft-tissue balancing, and a variable constraint provided by a standard cruciate-retaining (CR), posterior-stabilized (PS) or medialstabilized (MS) implant. However, in severe coronal deformities with stretched or incompetent collateral ligaments or when intraoperative balancing cannot be adequately achieved with standard implants, a higher degree of constraint may be required [7-9]. Condylarconstrained knee (CCK) prostheses are characterized by a tibial post higher and more squared than the PS one, that fits intimately between the condyles and provides medial-lateral and anteroposterior (AP) stability limiting varus-valgus and torsional moments $[10,11]$. Firstgeneration CCK implants were non-modular and were associated with a high rate of aseptic loosening [7] and a high rate of patellar complications including fracture, maltracking and osteonecrosis [12]. Second-generation CCK implants, with a redesigned patellofemoral articulation, provide increased medial-lateral stability and allow modular tibial and femoral stems in order to enhance fixation, provide stress relief and load-sharing within the host bone [13].

Theoretical disadvantages have been addressed to an increased level of constraint including greater risk of loosening caused by the transmission of the mechanical stress to the bone-cement interface and subsequent increased polyethylene insert wear, particularly of the tibial post, leading to a higher prevalence of osteolysis $[11,12,14-17]$. However, multiple studies have reported good short-to-midterm results of CCK implants in primary TKAs. In addition, range-of-motion (ROM) [17], clinical and radiographic outcomes seem to be comparable to standard PS implants in severe coronal deformity and ligamentous laxity $[11,12,15,18-23]$.

Therefore, the purpose of this study was to evaluate (1) the reoperation rates and survivorship for septic and aseptic causes, (2) radiographic outcomes, and (3) clinical outcomes based on Knee Society scores of a singledesign second-generation CCK implant used in primary TKAs with severe coronal deformity and/or medial-lateral instability.

\section{Patients and methods}

We retrospectively evaluated the records of 49 consecutive patients (54 knees) who underwent primary TKA using a single-design, second-generation condylar-constrained implant (NexGen LCCK; Zimmer, Warsaw, IN, USA) at one single institution between 2005 and 2012. The patients were identified from our institutional joint replacement database, ensuring a minimum follow-up of 5 years. We included all patients treated with primary knee arthroplasty in which the NexGen LCCK was implanted. During this period, 1,006 primary TKAs were performed at the same institution. Four patients (8.2\%) were lost during follow-up and three patients (6.1\%) died for reasons not related to index surgery, leaving 42 patients ( 47 knees) for final evaluation. The decision to use a CCK implant was left to the surgeon to decide depending on the patient's deformity, preoperative ligamentous stability, and intraoperative assessment of competency of the collateral ligaments and coronal stability after soft-tissue release was performed. In 12 knees (out of $47,26 \%$ ), the decision to use a CCK implant was taken preoperatively in either a valgus deformity $\geq 20^{\circ}$ ( 4 of 47 , $9 \%$; mean $22.5^{\circ}$, range $20-25^{\circ}$ ) or a varus deformity $\geq 20^{\circ}$ ( 8 of $47,17 \%$; mean $23.8^{\circ}$, range $20-30^{\circ}$ ) with or without collateral ligament failure. In the rest of the knees the decision was taken intraoperatively after attempting to balance the knees with a PS prosthesis; inadvertent intraoperative sectioning of the medial collateral ligament was reported in 2 knees (4.3\%). Preoperatively, standing femorotibial alignment was varus in 22 knees (46.8\%) averaging $13.3^{\circ}$ (range $5-30^{\circ}$ ). Valgus deformity was present in 20 knees $(42.6 \%)$ averaging $14.2^{\circ}$ (range 5-25 $5^{\circ}$. Overall, 42 knees $(89.4 \%)$ had $>5^{\circ}$ coronal deformity, including 17 knees (36.2\%) with major coronal deformity $>15^{\circ}$.The remaining 5 knees $(10.6 \%)$ were neutral or had little deformity. All patients were followed clinically and radiographically for a mean of 9 years (range 6-12 years). The cohort included 34 women (81\%) and 8 men with an average age of 72 years (range $43-86$ years) at the time of index surgery. Mean body mass index was $29 \mathrm{~kg} / \mathrm{cm}^{2}$ (range $18-37 \mathrm{~kg} / \mathrm{cm}^{2}$ ). There were 26 right $(55 \%)$ and 21 left knees (45\%). The underlying diagnosis that led to the initial primary TKA was osteoarthritis in 31 patients (36 knees, 76\%), post-traumatic arthritis in 7 patients (7 knees, 15\%), and rheumatoid arthritis in 4 patients (4 knees, 9\%) (Table 1).

The surgical technique for the implantation of a CCK implant has already been described [14, 19]. All the surgeries were performed by 2 experienced knee surgeons with preference for PS implants. The surgeries were performed under general or regional anesthesia. Tourniquet and a standard medial parapatellar approach via a midline skin incision were used in all cases. The distal femoral cut was performed using an intramedullary guide and the femoral rotation was set in neutral rotation relative to the transepicondylar axis. The tibial resection was aligned with an extramedullary guide perpendicular to the long axis of the tibia according to the surgical technique. The varus-valgus stability was evaluated at $0^{\circ}$ extension, mid-flexion $\left(30-40^{\circ}\right)$ and $90^{\circ}$ flexion 
Table 1 Demographic details of the 42 patients (47 knees) in the final cohort

\begin{tabular}{ll}
\hline Variable & Value \\
\hline Number of knees & 47 \\
Number of patients & 42 \\
Gender & \\
Female & $34(81 \%)$ \\
Male & $8(19 \%)$ \\
Side (number) & \\
Right & $26(55 \%)$ \\
Left & $21(45 \%)$ \\
Diagnosis (number of knees) & \\
Osteoarthritis & $36(76 \%)$ \\
Post-traumatic osteoarthritis & $7(9 \%)$ \\
Rheumatoid arthritis & $4(15 \%)$ \\
Body mass index (kg/m²) (range) & $29(18-37)$ \\
Mean age at surgery (range; years) & $72(43-86)$ \\
Varus deformity $\left(^{\circ}\right)($ range; mean) & \\
$5-30^{\circ}\left(13.3^{\circ}\right)$ & $22(46.8 \%)$ \\
$20-30^{\circ}$ & $8(17 \%)$ \\
Valgus deformity $\left({ }^{\circ}\right)$ (range; mean) & $20(42.6 \%)$ \\
$5-25^{\circ}\left(14.2^{\circ}\right)$ & $4(8.5 \%)$ \\
$20-25^{\circ}$ & \\
\hline
\end{tabular}

with a spacer block or a trial PS component. If the knee was considered unstable with a varus or valgus laxity of $>3 \mathrm{~mm}$ at any point of the ROM, after a concerted effort to obtain balance, a condylar-constrained implant $\left(\right.$ LCCK $^{\circledR}$; Zimmer) was used. Stem extensions were used in all cases (100\%). Short straight femoral stems sizing $15 \times 30 \mathrm{~mm}$ were used in 44 out of 47 knees (93.6\%), with $18 \times 100 \mathrm{~mm}$ stems being used in 2 knees $(4.3 \%)$ and $20 \times 100 \mathrm{~mm}$ in $1 \mathrm{knee}(2.1 \%)$. On the tibial side, a short straight $15 \times 30$ stem was used in 44 knees $(93.6 \%)$ and $14 \times 100 \mathrm{~mm}$ in 3 knees $(6.4 \%)-2$ of them were straight and 1 with offset. Short stems $(30 \mathrm{~mm})$ were fully cemented and cement was placed around the components and digitally impacted into the femoral and tibial metaphysis. Long stems $(100 \mathrm{~mm})$ were fixated with the hybrid technique. Eventual tibial or femoral bone defects were carefully assessed intraoperatively using the Anderson Orthopaedic Research Institute (AORI) Classification System [24] and rated as Type 2A in four tibias (4/47, $8.5 \%)$. In those cases, a finned precoat half block tibial augment (Zimmer) was used, sizing $5 \mathrm{~mm}$ in three cases and $10 \mathrm{~mm}$ in one case. Bone grafts were not used in any knee. Nine patellae (of $47,19.1 \%$ ) were resurfaced using a 3-peg all-polyethylene component with a reported mean size of $32 \mathrm{~mm}$. In the remaining 38 knees, the patella was left unresurfaced because of good bone quality. Patellar thermal denervation with electrocautery was performed in all cases. Antibiotic-loaded bone cement Simplex ${ }^{\mathrm{TM}} \mathrm{P}$ with Tobramycin Bone Cement (Stryker ${ }^{\circledR}$, Mahwah, NJ, USA) was used routinely in all patients. An intra-articular closed suction drain was used at the end of every surgical procedure and removed within 24-48 h postoperatively. Each patient received intravenous perioperative antibiotic prophylaxis, multimodal pain management and routine postoperative prophylaxis for thromboembolic disease with low-molecular-weight heparin. All patients were permitted weight-bearing as tolerated using crutches or a cane as necessary, beginning on the first postoperative day. The rehabilitation protocol with active ROM exercises and progressive weight-bearing was reached.

Patients were followed clinically and radiographically at the preoperative visit, 4 weeks postoperatively, and at 3 , 6 , and 12 months and then yearly thereafter. All patients were seen within 12 months of data collection for this study. Knee function was assessed with the Knee Society scoring system [25]. Radiographic review was performed by an independent fellowship-trained orthopedic surgeon according to the Knee Society TKA radiographic evaluation system [26] modified for long-stemmed revision prostheses [27], updated by Meneghini et al. [28]. A plain AP radiograph and a lateral knee plain radiograph were performed prior to discharge. Radiographs, consisting of standing AP, lateral, and Merchant views, were evaluated for any sign of loosening, including subsidence, cement mantle fractures, radiolucent zones, radiolucent lines, and implant migration. Fluoroscopic views were not used, but a standardized protocol with experienced radiology technicians was used.

Continuous variables were described using means and ranges. Categorical variables were described using absolute frequencies. To analyze differences in functional score (Knee Society score) collected before surgery and those collected at final follow-up, a two-tailed paired $t$-test and Wilcoxon signed-rank test were used. All statistical analyses were performed using SPSS v.26 (SPSS Chicago, IL, USA). $P$ values of $<0.05$ were considered significant.

Institutional review board approval was obtained before initiation of this study from the Catholic University of the Sacred Heart Research Ethics Board, Number $13397 / 14$.

\section{Results}

At a mean follow-up of 9 years, survivorship with reoperation for any reason as an end-point was $93.6 \%$. With implant revision for aseptic loosening or osteolysis as end-point, survivorship was $100 \%$. With implant revision for periprosthetic joint infection (PJI) as end-point, survivorship was $95.7 \%$. Three of the 47 patients (3/47 knees, 
$6.4 \%)$ required subsequent surgery. Two reoperations (4.3\%) were for PJI developed 14 months and 3 years from index surgery. Both of them underwent 2-stage revision after antibiotic spacer placement. The duration between the stages was 6 weeks for both cases [29]. One of them was further complicated by a reinfection 8 months after revision TKA, and underwent a second two-stage revision and subsequent above-knee amputation. One patient underwent arthroscopic debridement for patella clunk syndrome. No further problems were encountered by the patient. One patient with a valgus knee $\left(25^{\circ}\right)$ developed a postoperative neuroapraxia of the peroneal nerve that was completely resolved in 6 months.

There was no evidence of loosening or migration of any implant at the latest follow-up. On the immediate postoperative AP radiographs in 5 knees (out of 47, 10.6\%) there were radiolucent lines $<2 \mathrm{~mm}$ in thickness underneath the medial tibial tray at the bone-cement interface corresponding to zones 1 and $3 \mathrm{M}$ on the AP view. Those lines were considered partial, stable, and asymptomatic at final follow-up. No radiolucent lines were reported underneath the lateral tibial tray (zone 2) or around the stem extensions, when those were used (zone 4). Those lines were considered nonprogressive and asymptomatic at latest follow-up. The mean standing postoperative femorotibial alignment was $3.7^{\circ}$ of valgus (range between $1^{\circ}$ of varus and $6^{\circ}$ of valgus) and no patients had coronal deformity.

The mean Knee Society knee scores improved from 43 points (range $19-72$ points) preoperatively to 86 points (range $54-100$ points) postoperatively $(p<0.001)$. The mean Knee Society function scores improved from 40 points (range 17-69 points) preoperatively to 59 points (range $42-100$ points) postoperatively $(p<0.001)$. Preoperatively, the average flexion contracture was $7^{\circ}$ (range $0-15^{\circ}$ ) and the average flexion was $98^{\circ}$ (range $75-110^{\circ}$ ). At the time of the latest follow-up, the average flexion contracture was $2^{\circ}$ (range $\left.0-5^{\circ}\right)$ and the average flexion was $110^{\circ}$ (range $90-120^{\circ}$ ) (Table 2). No knees reported varus-valgus instability in flexion or extension.

\section{Discussion}

The findings of this study indicate that CCK implants in primary TKA with major coronal deformities and/or intraoperative inability to achieve an adequate stability with a standard PS implant, have a high overall survivorship (93.6\%) at a mean follow-up of 9 years and survivorship from aseptic loosening of $100 \%$, comparable with less constrained implants. These findings are in line with the recent systematic review and meta-analysis by Avino et al. [30], who reported significant clinical improvement in 3,620 CCK prostheses in primary TKA with a revision rate of $7 \%$ at 10 -year follow-up.
Table 2 Clinical outcomes of CCK implant in primary TKA

\begin{tabular}{lccc}
\hline & $\begin{array}{c}\text { Preoperative } \\
\text { Mean (range) }\end{array}$ & $\begin{array}{l}\text { Final follow-up } \\
\text { Mean (range) }\end{array}$ & P value \\
\hline KSKS & $43(19-17)$ & $86(54-100)$ & $<0.001$ \\
KSFS & $40(17-69)$ & $59(42-100)$ & $<0.001$ \\
Max flexion $\left(^{\circ}\right)$ & $98^{\circ}\left(75-105^{\circ}\right)$ & $108^{\circ}\left(90-120^{\circ}\right)$ & $<0.008$ \\
Flexion contracture & $7^{\circ}\left(0-15^{\circ}\right)$ & $2^{\circ}\left(0-5^{\circ}\right)$ & \\
\hline
\end{tabular}

KSKS Knee Society knee score, KSFS Knee Society function score

Primary TKA in the setting of severe coronal deformity and/or intraoperative inability to balance the knee represents a unique challenge in knee reconstruction. Standard implants with a low level of constraint and adequate soft-tissue balancing should be considered the first choice in order to achieve a well-balanced and stable knee in primary TKA. When soft-tissue techniques are inadequate to obtain intraoperative stability throughout all ROM, increased constraint is necessary to avoid the risk of instability and subsequent early revision. In fact, instability represents one of the most frequent causes of early failure leading to revision TKA reaching up to $27 \%$ at 5 years [5]. Indications for a CCK implant have been previously described and include severe axial deformities, collateral ligament insufficiency, severe bone loss and persistent laxity $>7-10 \mathrm{~mm}[7-9,31]$. However, agreement over the exact amount of instability that requires increased constrained has not been reached yet. In addition, while providing an increased varus-valgus stability compared to CR and PS designs, CCK implants ensure an acceptable midterm survivorship, and represent a more reliable option than hinged designs in primary TKAs. According to Abdulkarim et al. [32], the overall survivorship of rotating hinge implants in complex primary nononcologic TKA was $82 \%$ at a follow-up of 6-10 years.

Despite the disadvantages that have been associated with increased constraint, midterm survivorship from revision for aseptic loosening was $100 \%$, which is in line with previous studies of primary CCK that reported no cases of failure of the implants for aseptic loosening at midterm follow-up in primary TKA $[13,14,17,19,23$, $31,33]$. Our results compare favorably with those of other studies [11, 15, 22, 34-37] (Table 3). No complications related to the tibial post mechanism were reported at a mean follow-up of 9 years (range 6-12 years). In these studies, a survivorship of CCK implants in primary TKA of $>95 \%$ at midterm follow-up was reported. In addition, no cases of periprosthetic fractures were reported in our series despite a reported incidence up to $3.2 \%$ in a cohort of 127 primary TKAs with CCK implants [33]. The transmission of the mechanical stress to the bonecement interfaces may induce higher prevalence of loosening and subsequent osteolysis, especially when CCK 
Table 3 Studies of CCK implants in primary total knee arthroplasty with minimum 5-year follow-up

\begin{tabular}{|c|c|c|c|c|c|c|c|c|}
\hline $\begin{array}{l}\text { Authors } \\
\text { (year } \\
\text { of publication) }\end{array}$ & No. of knees & $\begin{array}{l}\text { No. } \\
\text { of primary } \\
\text { CCK }\end{array}$ & $\begin{array}{l}\text { Mean age } \\
\text { at index } \\
\text { (years) } \\
\text { (range) }\end{array}$ & $\begin{array}{l}\text { Mean follow-up } \\
\text { (years) (range) }\end{array}$ & $\begin{array}{l}\text { Reoperations } \\
\text { for aseptic } \\
\text { loosening } \\
\text { (rate) }\end{array}$ & $\begin{array}{l}\text { Reoperations } \\
\text { for infection } \\
\text { (rate) }\end{array}$ & $\begin{array}{l}\text { Reoperations } \\
\text { for } \\
\text { any reason } \\
\text { (rate) }\end{array}$ & $\begin{array}{l}\text { Infections } \\
\text { (rate) }\end{array}$ \\
\hline $\begin{array}{l}\text { Lachiewicz et al. } \\
\text { [12] }\end{array}$ & 42 & 20 & $67(40-91)$ & $9(5-16)$ & $1(5 \%)$ & $0(0 \%)$ & $1(5 \%)$ & $0(0 \%)$ \\
\hline $\begin{array}{l}\text { Lachiewicz et al. } \\
\text { [13] }\end{array}$ & 27 & 27 & 74 (28-94) & $5(2-12)$ & $0(0 \%)$ & $0(0 \%)$ & $2(7.4 \%)$ & $2(7.4 \%)$ \\
\hline Nam et al. [34] & 190 & 190 & 72 & 7 & $5(2.6 \%)$ & $1(0.5 \%)$ & $8(4.2 \%)$ & $1(0.5 \%)$ \\
\hline $\begin{array}{l}\text { Maynard et al. } \\
\text { [33] }\end{array}$ & 127 & 107 & $68(42-86)$ & $9(7-13)$ & $0(0 \%)$ & $2(1.6 \%)$ & $13(10.2 \%)$ & $4(3.1 \%)$ \\
\hline $\begin{array}{l}\text { Cholewinski et al. } \\
\text { [18] }\end{array}$ & 43 & 43 & $66(21-88)$ & $12(10-14)$ & $0(0 \%)$ & $2(4.7 \%)$ & $8(18.6 \%)$ & 4 (9.3\%) \\
\hline Luque et al. [11] & 89 & 89 & 71 & $7(2-8)$ & $2(2.2 \%)$ & $6(6.7 \%)$ & $11(12 \%)$ & $6(6.7 \%)$ \\
\hline Ruel et al. [35] & 142 & 142 & N/A & $5(2-10)$ & $7(4.9 \%)$ & $2(1.4 \%)$ & $14(9.9 \%)$ & $2(1.4 \%)$ \\
\hline Martin et al. [22] & 427 & 427 & 65 & $5(2-12)$ & $19(4.4 \%)$ & $5(1.2 \%)$ & 75 (17.6\%) & $26(6.1 \%)$ \\
\hline Feng et al. [19] & 48 & 15 & $61(29-81)$ & $6(3-8)$ & $0(0 \%)$ & $0(0 \%)$ & $0(0 \%)$ & $0(0 \%)$ \\
\hline Ye et al. [17] & 51 & 31 & $64(52-76)$ & $6(4-8)$ & $0(0 \%)$ & $1(3.2 \%)$ & $1(2 \%)$ & $1(3.2 \%)$ \\
\hline Tripathi et al. [37] & 100 & 100 & $59(45-70)$ & 7 & $1(1 \%)$ & $1(1 \%)$ & $3(3 \%)$ & $2(2 \%)$ \\
\hline $\begin{array}{l}\text { Siqueira et al. } \\
\text { [37] }\end{array}$ & 247 & 247 & 67 & $8(2-15)$ & $2(0.8 \%)$ & $13(5.3 \%)$ & $22(8.9 \%)$ & $13(5.3 \%)$ \\
\hline Li et al. [14] & 43 & 43 & $65(60-72)$ & $5(2-10)$ & $0(0 \%)$ & $0(0 \%)$ & $2(4.7 \%)$ & $0(0 \%)$ \\
\hline $\begin{array}{l}\text { Johnson et al. } \\
\text { [20] }\end{array}$ & 21 & 21 & $54(39-59)$ & $6(2-12)$ & $0(0 \%)$ & $0(0 \%)$ & $2(9.5 \%)$ & $0(0 \%)$ \\
\hline $\begin{array}{l}\text { Mancino et al. } \\
\text { (current study) }\end{array}$ & 47 & 47 & $72(43-86)$ & $9(6-12)$ & $0(0 \%)$ & $2(4.3 \%)$ & $3(6.4 \%)$ & $2(4.3 \%)$ \\
\hline
\end{tabular}

N/A not available

implants are used in younger and high-demand patients. Johnson et al. [20], in their series of 21 knees in relatively young patients (mean 54 years), reported implant survivorship of $100 \%$ at 6 -year follow-up and good functional outcomes despite a high incidence of stiffness (23.8\%). Their results suggest that primary CCK may represent a valid option not only in elderly and low-demand patients, but also in younger and more active patients. Furthermore, according to Badawy et al. [38], based on the Norwegian Arthroplasty Register, complex primary TKAs that require an increased level of constraint have higher reoperation and revision rates at 2- and 5-year follow-up attributable to factors other than implant design. They found that revisions were most commonly due to infection although the midterm survivorship was similar to unconstrained implants. However, in their study, CCK implants had midterm aseptic survivorship comparable to unconstrained implants. Recently, mid-level constrained (MLC) articular bearing has been introduced as a promising alternative in cases of mild coronal deformity. It is characterized by a wider post that limits rotation and varus-valgus lift-off to a few degrees but is less constrained than a CCK insert. Crawford et al. [39], in a cohort of 103 stemless MLC articular-bearing implants, reported overall survivorship of $97 \%$ and survivorship from revision for aseptic loosening or instability of $100 \%$ at a mean follow-up of 5 years. Those findings are supported by Dubin et al. [40] in their series of 57 MLC knees compared with 96 PS knees with a mean follow-up of 4 years. The authors reported 3.5\% (2 of 57) and 2\% ( 2 of 96 ) revision rates, respectively, in patients with mild coronal deformity.

Our overall complication rate was $8.5 \%$ (4 out of 47) and reoperation rate was $6.4 \%$ (3 out of 47 ). Infection was the most frequent complication and the most common reason for reoperation (2 of 47, 4.3\%). According to Jamsen et al. [41], in a register-based analysis, there was a trend showing an increased rate of infections in association with constrained and hinged prostheses at 3 years (1.2\%) compared with non-constrained CR or PS implants (0.7\%); this trend was significant especially for primary osteoarthritis. Our incidence of implant revision for PJI was $4.3 \%$, supporting the findings of a previous series where the most common reason for revision TKA was infection. Cholewinski et al. [18] and Luque et al. [11], reported revision rates for infection of $4.7 \%$ ( 2 of 43 knees) and $6.7 \%$ (6 of 99 knees) in their series of 43 and 99 knees at a mean follow-up of 12 and 7 years, respectively. Our results were higher than other studies of CCK implants in primary CCK 
reported in the current literature $[12-14,17,19,20,23$, 33] (Table 3). Interestingly, a recent retrospective analysis of $>18,000$ primary TKAs, reported a higher overall failure rate in patients with a primary CCK implant compared to a standard PS implant, with a hazard ratio of 1.99. This finding may be related to the fact that patients with CCK implants may present poor bone stock, ligamentous deficiency, or large preoperative deformities [42]. In addition, Costa et al. [43] compared the outcomes of 74 primary CCK implants with 73 primary PS implants. The authors reported a higher risk of early PJI in patients who underwent primary CCK compared to PS TKA, confirming that protracted surgical time attributed to greater difficulty in exposure and in achieving adequate balance, representing a predisposing factor for PJI.

Radiolucent lines were found in $10.6 \%$ of the cases. All of them were $<2 \mathrm{~mm}$ in thickness and found underneath the medial tibial tray at the bone-cement interface corresponding to zones 1 and $3 \mathrm{M}$ on the AP view according to Meneghini et al. [28]. Those lines were considered partial and stable according to the same criteria, and asymptomatic at final follow-up. No radiolucent lines were reported underneath the lateral tibial tray (zone 2) or around the stem extensions when those were used (zone 4). In addition, no radiolucent lines were reported around the femoral component. These findings were in line with those reported by Maynard et al. (9.4\%) [33] and Lachiewicz et al. (11\%) [13]. The authors reported an incidence of radiolucent lines of 9.4\% (14 of 127) and 11\% (3 of 27) in their series of 127 and 27 knees at a mean follow-up of 9 and 5 years, respectively. An incidence of non-progressive radiolucent lines underneath the tibial component in primary CCK has been reported in up to $47 \%$ of cases [12, 18], likely suggesting incomplete cement pressurization.

The Knee Society knee score improved by an of average 43 points from the preoperative state to the latest follow-up, and the functional score improved by a mean 19 points. The improvement between mean preand postoperative values was comparable with what has been previously reported in other studies of primary CCK with significant improvement in clinical outcomes and flexion ROM [11-13, 17, 18, 20, 23]. The ROM improved by mean $10^{\circ}$ of flexion, in line with what is reported in the literature [12, 17, 20, 23, 33], and higher than reported by Feng et al. [19]. Flexion contracture decreased from mean $7^{\circ}$ in the preoperative evaluation to mean $2^{\circ}$ at final follow-up. Puah et al. [15] recently reported no significant difference in ROM or functional scores between primary CCK implants and PS implants at 6 months and 2 years.
There are some limitations to this study. First, the current study is a retrospective study with all the limitations of this type of design. Second, the patient cohort was relatively small and lacked a control group matched for baseline characteristics with lower constraint implants. Third, some selection bias might have been detected since intraoperative indication to a CCK implant was left to the surgeon's preference and experience. Fourth, the implants were used in relatively elderly patients (mean age 72 years) with relatively low demands; however, the results may differ in younger, more active and demanding patients.

\section{Conclusion}

CCK implants in primary TKA can be considered a viable option in cases of severe coronal deformities or when intraoperative stability is not achievable with standard implants (CR, PS, MS), providing good survivorship and functional outcomes at midterm follow-up, comparable with less constrained implants. With the recent introduction of mid-level constrained implants the need for CCK implants in primary TKA may decrease. However, a higher degree of constraint should be used cautiously and patients should be carefully selected, leaving the first choice to implants with a lower level of constraint since increased mechanical stresses may affect long-term survivorship.

\section{Abbreviations}

TKA: Total knee arthroplasty; CR: Cruciate-retaining; PS: Posterior-stabilized; MS: Medial-stabilized; CCK: Condylar-constrained knee; ROM: Range of movement; AORI: Anderson Orthopaedic Research Institute; KSS: Knee Society score.

\section{Aknowledgements}

Not applicable.

\section{Authors Contributions}

FM, IDM, AB, CDI designed the study, collected analyzed and interpreted the data. FM and IDM drafted the manuscript. MFS, IDM, GM revised it critically for important intellectual content. VDS: final revision of the manuscript. All authors read and approved the final manuscript.

\section{Funding}

No benefits of any form have been received or will be received from a commercial party related directly or indirectly to the subject of this article.

\section{Availability of data and materials}

The datasets generated and/or analysed during the current study are not publicly available due to the high volume of data but are available from the corresponding author on reasonable request. This work was performed at the Adult Reconstruction and Joint Replacement Service, Division of Orthopaedics and Traumatology, Department of Aging, Neurological, Orthopaedic and Head-Neck studies, Fondazione Policlinico Universitario Agostino Gemelli IRCCS, Roma, Italy

\section{Ethics approval and consent to participate}

All procedures performed were in accordance with the 1964 Helsinki Declaration and its later amendments or comparable ethical standards. Institutional 
Review Board (IRB) approval was obtained before initiation of this study from the Catholic University of the Sacred Heart Research Ethics Board, Number 13397/14.

\section{Consent for publication}

Not applicable.

\section{Competing interests}

The authors declare no potential conflict of interests.

\section{Author details}

${ }^{1}$ Division of Orthopaedics and Traumatology, Department of Aging, Neurological, Orthopaedic and Head-Neck Studies, Fondazione Policlinico Universitario Agostino Gemelli IRCCS, 00168 Rome, Italy. ${ }^{2}$ Università Cattolica del Sacro Cuore, Largo Francesco Vito 1, 00168 Rome, Italy. ${ }^{3}$ Department of Orthopaedics, Children's Hospital "Bambino Gesù", Rome, Italy. ${ }^{4}$ Villa Stuart Sport Clinic, FIFA Medical Centre of Excellence, Rome, Italy. ${ }^{5}$ Department of Orthopaedics and Traumatology, Mater Olbia Hospital, Olbia, Italy.

\section{Received: 9 October 2020 Accepted: 18 November 2020} Published online: 02 December 2020

\section{References}

1. Kurtz S, Ong K, Lau E, Mowat F, Halpern M (2007) Projections of primary and revision hip and knee arthroplasty in the United States from 2005 to 2030. J Bone Jt Surg 89(4):780-785. https://doi.org/10.2106/JBJS.F.00222

2. Australian Orthopeaedic Association National Joint Replacement Registry, (2018) 2018 Annual Report. Available via DIALOG.http://aoanjrr.sahmr i.com/annual-reports-2018. Accessed 15 March 2020

3. The 2019 Annual Report of The American Joint Replacement Registry. (2019) Available via DIALOG.http://www.aaos.org/registries/publications/ ajrr-annual-report/. Accessed 15 March 2020

4. Del Gaizo DJ, Della Valle CJ (2011) Instability in primary total knee arthroplasty. Orthopedics 34(9):519-521. https://doi.org/10.3928/01477 447-20110714-46

5. Fehring TK, Odum S, Griffin WL, Mason JB, Nadaud M (2001) Early failures in total knee arthroplasty. Clin Orthop Relat Res 392:315-318. https://doi. org/10.1097/00003086-200111000-00041

6. Hossain F, Patel S, Haddad FS (2010) Midterm assessment of causes and results of revision total knee arthroplasty. Clin Orthop Relat Res 468(5):1221-1228. https://doi.org/10.1007/s11999-009-1204-0

7. Donaldson WF 3rd, Sculco TP, Insall JN, Ranawat CS (1988) Total condylar III knee prosthesis. Long-term follow-up study. Clin Orthop Relat Res 226:21-28

8. Insall JN, Ranawat CS, Aglietti P, Shine J (1976) A comparison of four models of total knee-replacement prostheses. J Bone Joint Surg Am 58(6):754-765

9. Sculco TP (2006) The role of constraint in total knee arthoplasty. J Arthroplasty 21:54-56. https://doi.org/10.1016/j.arth.2006.02.166

10. Anderson JA, Baldini A, MacDonald JH, Pellicci PM, Sculco TP (2006) Primary constrained condylar knee arthroplasty without stem extensions for the valgus knee. Clin Orthop Relat Res 442:199-203. https://doi. org/10.1097/01.blo.0000185675.99696.29

11. Luque R, Rizo B, Urda A, Garcia-Crespo R, Moro E, López-Durán L (2015) Primary modular total knee replacement in severe and unstable osteoarthritis. Predictive factors for failure. Int Orthop 39(11):2125-2133. https:// doi.org/10.1007/s00264-015-2807-6

12. Lachiewicz PF, Soileau ES (2006) Ten-year survival and clinical results of constrained components in primary total knee arthroplasty. J Arthroplasty 21(6):803-808. https://doi.org/10.1016/j.arth.2005.09.008

13. Lachiewicz PF, Soileau ES (2011) Results of a second-generation constrained condylar prosthesis in primary total knee arthroplasty. J Arthroplasty 26(8):1228-1231. https://doi.org/10.1016/j.arth.2011.05.010

14. Li F, Liu N, Li Z, Wood KB, Tian H (2019) Abnormally high dislocation rate following constrained condylar knee arthroplasty for valgus knee: A casecontrol study. J Orthop Surg Res 14(1):268. https://doi.org/10.1186/s1301 8-019-1325-4

15. Puah KL, Chong HC, Foo LSS, Lo N-N, Yeo S-J (2018) Clinical and functional outcomes: primary constrained condylar knee arthroplasty compared with posterior stabilized knee Arthroplasty. JAAOS Glob Res Rev 2(2):e084. https://doi.org/10.5435/JAAOSGlobal-D-17-00084

16. Rai S, Liu X, Feng X, Rai B, Tamang N, Wang J et al (2018) Primary total knee arthroplasty using constrained condylar knee design for severe deformity and stiffness of knee secondary to post-traumatic arthritis. J Orthop Surg Res 13:67. https://doi.org/10.1186/s13018-018-0761-x

17. Ye CY, Xue DT, Jiang S, He RX. (2016) Results of a second-generation constrained condylar prosthesis in complex primary and revision total knee arthroplasty: a mean 5.5-year follow-up. Chin Med J (Engl) 129(11):13341339 doi: https://doi.org/10.4103/0366-6999.182845

18. Cholewinski P, Putman S, Vasseur L, Migaud H, Duhamel A, Behal H et al (2015) Long-term outcomes of primary constrained condylar knee arthroplasty. Orthop Traumatol Surg Res 101(4):449-454. https://doi. org/10.1016/j.otsr.2015.01.020

19. Feng XB, Yang C, Fu DH, Ye SN, Liu XZ, Chen Z et al (2016) Mid-term outcomes of primary constrained condylar knee arthroplasty for severe knee deformity. J Huazhong Univ Sci Technol - Med Sci 36(2):231-236. https:// doi.org/10.1007/s11596-016-1572-0

20. Johnson DB, Triplet JJ, Gaines DR, Gupta A, Unverferth KL (2019) Mid-term outcomes following primary semi-constrained total knee arthroplasty in patients less than 60 years old, a retrospective review. Knee 26(3):714719. https://doi.org/10.1016/j.knee.2019.02.001

21. King BR, Gladnick BP, Lee YY, Lyman S, Della Valle AG (2014) Range of motion and function are not affected by increased post constraint in patients undergoing posterior stabilized total knee arthroplasty. Knee 21(1):194-198. https://doi.org/10.1016/j.knee.2013.07.002

22. Martin JR, Beahrs TR, Stuhlman CR, Trousdale RT (2016) Complex primary total knee arthroplasty: long-term outcomes. J Bone Joint Surg Am 98(17):1459-1470. https://doi.org/10.2106/JBJS.15.01173

23. Sabatini L, Risitano S, Rissolio L, Bonani A, Atzori F, Massè A (2017) Condylar constrained system in primary total knee replacement: our experience and literature review. Ann Transl Med 5(6):135. https://doi.org/10.21037/ atm.2017.03.29

24. Engh GA, Ammeen DJ (1999) Bone loss with revision total knee arthroplasty: defect classification and alternatives for reconstruction. Instr Course Lect 48:167-175

25. Insall JN, Dorr LD, Scott RD, Scott WN (1989) Rationale of the Knee Society clinical rating system. Clin Orthop Relat Res 248:13-14

26. Ewald F, C. (1989) Roentgenographic evaluation and scoring system. Clncal Orthop Related Res 248:9-12

27. Murray PB, Rand JA, Hanssen AD (1994) Cemented long-stem revision total knee arthroplasty. Clin Orthop Relat Res 309:116-123

28. Meneghini RM, Mont MA, Backstein DB, Bourne RB, Dennis DA, Scuderi GR (2015) Development of a modern Knee Society radiographic evaluation system and methodology for total knee arthroplasty. J Arthroplasty 30(12):2311-2314. https://doi.org/10.1016/j.arth.2015.05.049

29. Jacobs C, Christensen CP, Berend ME (2009) Static and mobile antibioticimpregnated cement spacers for the management of prosthetic joint infection. J Am Acad Orthop Surg 17(6):356-368. https://doi. org/10.5435/00124635-200906000-00004

30. Avino RJ, King CA, Landy DC, Martell JM (2020) Varus-valgus constraint in primary total knee arthroplasty: a short-term solution but will it last? J Arthroplasty 35(3):741-746.e2. https://doi.org/10.1016/j.arth.2019.09.048

31. Callaghan JJ, O'Rourke MR, Liu SS (2005) The role of implant constraint in revision total knee arthroplasty: not too little, not too much. J Arthroplasty 20(4):41-43. https://doi.org/10.1016/j.arth.2005.03.008

32. Abdulkarim A, Keane A, Hu SY, Glen L, Murphy DJ (2019) Rotating-hinge knee prosthesis as a viable option in primary surgery: Literature review \& meta-analysis. Orthop Traumatol Surg Res 105(7):1351-1359. https://doi. org/10.1016/j.otsr.2019.08.012

33. Maynard LM, Sauber TJ, Kostopoulos VK, Lavigne GS, Sewecke JJ, Sotereanos NG (2014) Survival of primary condylar-constrained total knee arthroplasty at a minimum of 7 years. J Arthroplasty 29(6):1197-1201. https://doi.org/10.1016/j.arth.2013.11.018

34. Nam D, Umunna BP, Cross MB, Reinhardt KR, Duggal S, Cornell CN (2012) Clinical results and failure mechanisms of a nonmodular constrained knee without stem extensions. HSS 8(2):96-102. https://doi.org/10.1007/ s11420-012-9277-9

35. Ruel A, Ortiz P, Westrich G (2016) Five year survivorship of primary nonmodular stemless constrained knee arthroplasty. Knee 23(4):716-718. https://doi.org/10.1016/j.knee.2015.10.010 
36. Siqueira MBP, Jacob P, McLaughlin J, Klika AK, Molloy R, Higuera CA et al (2017) The varus-valgus constrained knee implant: survivorship and outcomes. J Knee Surg 30(5):484-492. https://doi.org/10.1055/s-0036-15933 61

37. Tripathi MS, Heinle CC, Manaqibwala MI, Tria AJ Jr (2016) The utility of increased constraint in primary total knee arthroplasty for obese patients. Orthop Clin North Am 47(1):51-55. https://doi.org/10.1016/j. ocl.2015.08.007

38. Badawy M, Fenstad AM, Furnes O (2019) Primary constrained and hinged total knee arthroplasty: 2- and 5-year revision risk compared with unconstrained total knee arthroplasty: a report on 401 cases from the Norwegian Arthroplasty Register 1994-2017. Acta Orthop 90(5):467-472. https://doi.org/10.1080/17453674.2019.1627638

39. Crawford DA, Law JI, Lombardi AV Jr, Berend KR (2018) Midlevel constraint without stem extensions in primary total knee arthroplasty provides stability without compromising fixation. J Arthroplasty 33(9):2800-2803. https://doi.org/10.1016/j.arth.2018.03.070

40. Dubin JA, Westrich GH (2020) Mid-level constraint may correct coronal plane imbalance without compromising patient function in patients with severe osteoarthritis. J Orthop 21:84-87. https://doi.org/10.1016/j. jor.2020.03.022

41. Jämsen E, Huhtala H, Puolakka T, Moilanen T (2009) Risk factors for infection after knee arthroplasty. A register-based analysis of 43,149 cases. J Bone Jt Surg Am 91(1):38-47. https://doi.org/10.2106/JBJS.G.01686

42. Pitta M, Esposito Cl, Li Z, Lee YY, Wright TM, Padgett DE (2018) Failure after modern total knee arthroplasty: a prospective study of 18,065 knees. J Arthroplasty 33(2):407-414. https://doi.org/10.1016/j.arth.2017.09.041

43. Costa GC, Lo Presti M, Agrò G, Vasco C, Cialdella S, Casali M et al (2020) Difficult primary total knee arthroplasty requiring a varus-valgus constrained implant is at higher risk of periprosthetic infection. Knee Surg Sports Traumatol Arthrosc (in press). https://doi.org/10.1007/s00167-02005866-0

\section{Publisher's Note}

Springer Nature remains neutral with regard to jurisdictional claims in published maps and institutional affiliations.

\section{Submit your manuscript to a SpringerOpen ${ }^{\circ}$ journal and benefit from:}

- Convenient online submission

- Rigorous peer review

- Open access: articles freely available online

- High visibility within the field

- Retaining the copyright to your article

Submit your next manuscript at $\boldsymbol{\nabla}$ springeropen.com 